\title{
Protective Effect of Trimetazidine on Potassium Ion Homeostasis in Myocardial Tissue in Mice with Heart Failure
}

\author{
Kaijing Yang, ${ }^{1}$ Yitao Xue $\mathbb{D}^{1,2}$ Miao Yu, ${ }^{1}$ Huachen Jiao, ${ }^{1,2}$ Yan Li ${ }^{1},{ }^{2}$ Xijin Wei, ${ }^{2}$ \\ Wenwen Liu, ${ }^{3}$ Yang Sun, ${ }^{4}$ Nannan Chen, ${ }^{1}$ Linlin Song, ${ }^{1}$ Ting Yu, ${ }^{1}$ Kaiming Chen, \\ and Dadong Guo $\mathbb{D}^{5}$ \\ ${ }^{1}$ Shandong University of Traditional Chinese Medicine, Jinan 250011, China \\ ${ }^{2}$ Affiliated Hospital of Shandong University of Traditional Chinese Medicine, Jinan 250011, China \\ ${ }^{3}$ Traditional Chinese Medicine Hospital of Jimo District, Qingdao 266200, China \\ ${ }^{4}$ Department of Laboratory of Molecular Diagnosis and Regenerative Medicine, Affiliated Hospital of Qingdao University, \\ Qingdao 266000, China \\ ${ }^{5}$ Shandong Provincial Key Laboratory of Integrated Traditional Chinese and Western Medicine for Prevention and Treatment of \\ Eye Diseases; Shandong Academy of Eye Disease Prevention and Therapy; Affiliated Eye Hospital of Shandong University of \\ Traditional Chinese Medicine, Jinan 250002, China
}

Correspondence should be addressed to Yitao Xue; xytsdzydfy@126.com and Dadong Guo; dadonggene@163.com

Received 22 September 2021; Revised 28 December 2021; Accepted 29 December 2021; Published 19 January 2022

Academic Editor: Zhizhong Song

Copyright (C) 2022 Kaijing Yang et al. This is an open access article distributed under the Creative Commons Attribution License, which permits unrestricted use, distribution, and reproduction in any medium, provided the original work is properly cited.

\begin{abstract}
The occurrence of heart failure (HF) is closely correlated with the disturbance of mitochondrial energy metabolism, and trimetazidine (TMZ) has been regarded as an effective agent in treating HF. Intracellular potassium ion $\left(\mathrm{K}^{+}\right)$homeostasis, which is modulated by $\mathrm{K}^{+}$ channels and transporters, is crucial for maintaining normal myocardial function and can be disrupted by HF. This study is aimed at exploring the protective effect of TMZ on $\mathrm{K}^{+}$homeostasis within myocardial tissue in mice with HF. We observed the pathological changes of myocardial tissue under microscopes and further measured the content of adenosine triphosphate (ATP), the activity of $\mathrm{Na}^{+}-\mathrm{K}^{+}$ATPase, and the expression of ATP $1 \alpha 1$ at the mRNA and protein levels. Moreover, we also analyzed the changes in $\mathrm{K}^{+}$ flux across the myocardial tissue in mice. As a result, we found that there was a large amount of myocardial fiber lysis and fracture in HF myocardial tissue. Meanwhile, the potassium flux of mice with HF was reduced, and the expression of ATP $1 \alpha 1$, the activity of $\mathrm{Na}^{+}-\mathrm{K}^{+}$ATPase, and the supply and delivery of ATP were also decreased. In contrast, TMZ can effectively treat HF by restoring $\mathrm{K}^{+}$homeostasis in the local microenvironment of myocardial tissues.
\end{abstract}

\section{Introduction}

Heart failure (HF) is defined as a complex clinical syndrome in which ventricular filling or ejection function is damaged due to various organic or functional heart diseases, accompanied by reduced cardiac output. HF is the main cause of death from cardiovascular diseases and seriously threatens human life and health, affecting approximately 23 million patients worldwide $[1,2]$. To date, a large amount of evidence has shown that the occurrence of HF is closely corre- lated with mitochondrial dysfunction [3]. The heart produces myocardial energy through the oxidation of glucose and fatty acids, thereby regulating heart function and efficiency [4]. In HF, the oxidative metabolism of mitochondria is impaired, and the oxidation of mitochondrial fatty acids exceeds the oxidation of mitochondrial glucose, thus causing pyruvate to accumulate and convert into lactic acid, further accelerating cell apoptosis $[5,6]$. Trimetazidine (TMZ) is a fatty acid oxidation inhibitor that inhibits 3ketoacyl CoA thiolase, and it can enhance glucose oxidation 
and improve cardiac function [7]. Li et al. found that TMZ can convert the utilization of metabolic substrates from fatty acids to glucose to meet energy requirements, thereby reducing the metabolic remodeling of rats with HF [8].

The heart is an organ with high energy demand and needs much energy (that it consumes in the form of adenosine triphosphate which comes from the oxidative metabolism of mitochondria) to maintain its vitality and pump function [9]. Adenosine triphosphate (ATP), in fact, acts as the "molecular currency" for energy transfer in cells, and mitochondria are at the core of ATP production. $\mathrm{Na}^{+}-\mathrm{K}^{+}$ATPase is a common target of drugs and diseases that is closely related to energy metabolism [10]; moreover, it is also involved in the main efflux mechanism of $\mathrm{Na}^{+}$in cardiomyocytes. ATP $1 \alpha 1$ belongs to the $\mathrm{Na}^{+}-\mathrm{K}^{+}$ATPase subfamily and is regarded to be uniformly expressed in all cells [11]. As a muscle membrane pump, $\mathrm{Na}^{+}-$ $\mathrm{K}^{+}$ATPase maintains a transmembrane $\mathrm{Na}^{+}$gradient, contributing to ion homeostasis $[12,13]$. It is known that the cardiac action potential is generated by the coordinated activation and inactivation of ion channels, which conduct depolarization $\left(\mathrm{Na}^{+}\right.$and $\left.\mathrm{Ca}^{2+}\right)$ currents and repolarization $\left(\mathrm{K}^{+}\right)$currents [14]. In HF models of humans and other animal species, the level of $\mathrm{Na}^{+}$in cardiomyocytes is upregulated, whereas the outward $\mathrm{K}^{+}$ current is downregulated [15]. Hegyi et al. found that the reduction of the $\mathrm{K}^{+}$current, enhancement of the $\mathrm{Na}^{+} / \mathrm{Ca}^{2+}$ exchange, and elevation of the subsequent $\mathrm{Na}^{+}$current contribute to extending the duration of the HF action potential [16]. Hypokalemia (serum $\left[\mathrm{K}^{+}\right]<3.5 \mathrm{~mm}$ ) also exhibits a significant inhibitory effect on $\mathrm{Na}^{+}-\mathrm{K}^{+}$ATPase [17]. Moreover, studies have also shown that the level of $\mathrm{Na}^{+}-\mathrm{K}^{+}$ATPase in patients with $\mathrm{HF}$ can be reduced by $40 \%$ [18]. Wang et al. found that polydatin and vitamin $\mathrm{C}$ can increase the activity of $\mathrm{Na}^{+}-\mathrm{K}^{+}$ ATPase in the myocardium of rats with HF induced by doxorubicin (DOX) and increase the content of ATP through antioxidant effects and energy improvement, thus enhancing myocardial function and exerting a protective role [19]. In addition, Mewes et al. showed that ATP concentration increases with incremental increases in intracellular sodium concentration $\left(\left[\mathrm{Na}^{+}\right]\right)$to $150 \mathrm{mM}$, accompanied by the elevation of $\mathrm{Na}^{+}-\mathrm{K}^{+}$-ATPase transcription activity [20]. Therefore, the occurrence of HF is closely associated with energy metabolism disorders and the regulatory role of $\mathrm{Na}^{+}-\mathrm{K}^{+}$ATPase.

Clinical experiments have proven that TMZ, an antiangina pectoris drug, has shown cardioprotective effects in many cardiovascular diseases [21]. It can efficiently reduce brain natriuretic peptide (BNP) levels in HF patients [22]. TMZ can also improve the classification of NYHA heart function (NYHA) levels and increase exercise tolerance to enhance HF patients' activity tolerance and improve their quality of life [23]. In the present study, we speculated that TMZ could enhance myocardial cell $\mathrm{Na}^{+}-\mathrm{K}^{+}$ATPase activity and maintain $\mathrm{K}^{+}$homeostasis to ensure the supply and delivery of ATP in an HF mouse model and increase the expression of ATP $1 \alpha 1$ to protect the structure and function of mitochondria, thus improving heart energy metabolism to treat HF. In this regard, we explored the molecular mechanisms of TMZ in the treatment of HF. Our investigations will pave the way for TMZ to treat HF in clinical practice.

\section{Materials and Methods}

\subsection{Experimental Materials}

2.1.1. Experimental Agents. TMZ hydrochloride tablets were supplied by Servier Pharmaceutical Co., Ltd. (Tianjin, China), while doxorubicin was produced by Dalian Meilun Biotechnology Co., Ltd. (Dalian, China).

2.1.2. Experimental Animals. The entire experiment was approved by the Experimental Animal Ethics Committee of the Affiliated Hospital of Shandong University of Traditional Chinese Medicine (AWE-2019-01). The study design was aimed at reducing the discomfort and stress of the animals. All rats were fed and maintained in accordance with the "Guiding Opinions on Treating Laboratory animals" issued by the Ministry of Science and Technology of the People's Republic of China (2006). In this study, 60 male C57BL/6 mice (8 weeks old, weighing approximately $20 \mathrm{~g}$ ) were provided by Beijing Vital River Laboratory Animal Co., Ltd. (Beijing, China). The animal license number was SCXK (Beijing) 2016-0006, and the certificate number was No. 11400700381280.

2.1.3. Animal Models and Groupings. Sixty healthy C57BL/6 mice ( 8 weeks old, male) were randomly divided into a normal control (NC) group, a HF model (MOD) group, and a TMZ treatment (TMZ) group. All mice were injected with doxorubicin $(3 \mathrm{mg} / \mathrm{kg} / \mathrm{biw})$ for 6 weeks to induce HF [24], except those in the NC group. BNP and cardiac ultrasound were used to verify whether HF was successfully induced. On day 1 of the second week, the mice in the TMZ group received TMZ $(10 \mathrm{mg} / \mathrm{kg} / \mathrm{d})$ for 6 continuous weeks by oral gavage to treat $\mathrm{HF}$, while those in the NC and MOD groups received the same volume of sterilized distilled water. Six weeks later, the mice in each group were fasted for $12 \mathrm{~h}$ after the last administration and were weighed and anesthetized by intraperitoneal injection of $3 \%$ sodium pentobarbital $(50 \mathrm{mg} / \mathrm{kg})$. Subsequently, the thoracic cavity was cut, the heart was quickly isolated, and myocardial tissue samples were collected.

2.2. Echocardiography. The mice in each group received relevant treatments for 6 weeks. At the indicated time, the mice received an injection of sodium $1 \%$ pentobarbital $(50 \mathrm{mg} / \mathrm{kg})$ for the aim of anesthetization. Next, the changes in the left ventricular ejection fraction (LVEF) of the mice were detected by an ultrasound B-mode system (M5 Vet, Mindray Biomedical Electronics Co., Ltd., Shenzhen, China).

2.3. BNP Levels. Prior to sacrifice, the mice were anesthetized by intraperitoneal injection of $3 \%$ pentobarbital $(50 \mathrm{mg} / \mathrm{kg})$ until they were in a deep coma and the pain reflex disappeared. Subsequently, $1 \mathrm{ml}$ of blood from the inferior vena was collected and centrifuged at $600 \mathrm{~g}$ for $10 \mathrm{~min}$ to collect the plasma. A Mouse Brain Natriuretic Peptide Enzymelinked Immunoassay Kit (Wuhan Huamei Biological Engineering Co., Ltd, Wuhan, China) was used to determine the BNP level to validate whether the model was successfully established. 
2.4. Histopathological Staining. After different interventions for 6 weeks, mice in each group $(n=5)$ were anesthetized, and the myocardial tissues were extracted, placed in cold 24-well plates (NEST Biotechnology, Wuxi, China), fixed with 4\% paraformaldehyde, and then embedded in paraffin. After cutting into $5 \mu \mathrm{m}$ sections, each section was stained with hematoxylin and eosin (H\&E) solution. Finally, the slides were observed under an optical microscope (Eclipse55i; Nikon, Tokyo, Japan) with NIS elements D3.2 software (Nikon, Tokyo, Japan).

2.5. Transmission Electron Microscopy. After anesthesia with $3 \%$ sodium pentobarbital, the left ventricular myocardium was cut and immediately placed in $4 \%$ glutaraldehyde fixative ( $<2 \mathrm{~min})$. After fixation, dehydration, embedding, and polymerization, ultrathin sections of $60-80 \mathrm{~nm}$ were made, and lead citrate staining was performed. Finally, a transmission electron microscope (HITACHI, Japan) was used to observe the mitochondrial ultrastructure of cardiomyocytes.

2.6. ATP Levels. In this study, we measured the ATP level in myocardial tissues in each group $(n=6)$. The mice were sacrificed after anesthesia, and the myocardial tissues were isolated. Then, the tissues and $0.9 \% \mathrm{NaCl}$ (weight $(\mathrm{g})$ : volume $(\mathrm{ml})=1: 4$ ) solution were placed into enzyme-free $5 \mathrm{ml}$ plastic tubes (NEST Biotechnology, Wuxi, China), homogenized for $10 \mathrm{~min}$, and centrifuged at $2500 \mathrm{rpm}$ at $4^{\circ} \mathrm{C}$ for $10 \mathrm{~min}$ to collect the supernatants. The ATP level was measured with an ATP determination kit (Nanjing Jiancheng Institute of Bioengineering, Nanjing, China) in accordance with the manufacturer's instructions. The protein level of the supernatants in each group was measured using a BCA protein concentration measurement kit (Sparkjade Science Co., Ltd., China).

2.7. $\mathrm{Na}^{+}-\mathrm{K}^{+}$ATPase $m R N A$ Levels. Total RNA in each group $(n=5)$ was extracted from the cardiac muscle tissue using an RNA tissue/cell rapid extraction kit (Shandong Sparkjade Science Co., Ltd., China) and quantified with a K5600 spectrophotometer (K5600; Beijing Kaiao Technology Development Co., Ltd., Beijing, China). Then, a HiScriptIIQ RT SuperMix for Q-PCR kit (Vazyme Biotechnology Co., Ltd., Nanjing, China) was used to synthesize complementary DNA (cDNA), and SYBR Q-PCR Master Mix (Vazyme Biotechnology Co., Ltd., Nanjing, China) was used to amplify the target gene using a LightCycler 480 II instrument (Roche Diagnostics, Mannheim, Germany). The target-specific primers are listed in Table 1. The Q-PCR program was set as follows: 1 cycle at $95^{\circ} \mathrm{C}$ for $30 \mathrm{~s}$, followed by 45 cycles at $95^{\circ} \mathrm{C}$ for $10 \mathrm{~s}$ and $61^{\circ} \mathrm{C}$ for $30 \mathrm{~s}$. After Q-PCR detection, the $2^{-\Delta \Delta \mathrm{Ct}}$ method was used to calculate the level of the target gene.

2.8. $\mathrm{Na}^{+}-\mathrm{K}^{+}$ATPase Protein Levels. To measure the $\mathrm{Na}^{+}-\mathrm{K}^{+}$ ATPase protein level in myocardial tissue in each group, enzyme-linked immunosorbent assay (ELISA) was carried out. In the present study, mice in each group $(n=6)$ were sacrificed, and then, the myocardial tissue and phosphate-buffered saline (PBS, $\mathrm{pH} 7.4)$ solution (weight $(\mathrm{g})$ : volume $(\mathrm{ml})=1: 9$ ) were placed into enzyme-free $5 \mathrm{ml}$ plastic tubes (NEST Biotechnology, Wuxi, China), homogenized for $20 \mathrm{~min}$, and centrifuged at $3000 \mathrm{rpm}$ at $4^{\circ} \mathrm{C}$ for $20 \mathrm{~min}$. Then, the supernatants were collected. Subsequently, a mouse sodium-potassium
TABle 1: ATP $1 \alpha 1$ primer sequences for quantitative PCR.

\begin{tabular}{lc}
\hline Gene & \multicolumn{1}{c}{ Primer sequences } \\
\hline ATP1 $\alpha 1$ & F: $5^{\prime}$-GAGGCAGCCCAGAAACCCCAAAAC-3' \\
ATP1 $\alpha 1$ & R: $5^{\prime}$-TCGGCCCACTGCACTACCACAATA-3' \\
GAPDH & F: $5^{\prime}$-ACGGCAAATTCAACGGCACAGTCA-3' \\
GAPDH & R: $5^{\prime}$-CGGCAGAAGGGGCGGAGATG-3' \\
\hline
\end{tabular}

ATPase transporter a1 (ATP1 $\alpha 1$ ) ELISA kit (Shanghai Jianglai Biotechnology Co., Ltd., Shanghai, China) was used to detect the ATP $1 \alpha 1$ protein level. At the same time, the protein level of the supernatants in each group was measured using a BCA protein concentration measurement kit (Shandong Sparkjade Science Co., Ltd., China) according to the manufacturer's instructions. The absorbance of the samples was measured at $450 \mathrm{~nm}$ using a microplate reader (Elx800, BioTek Instruments, USA). Each experiment was repeated three times.

2.9. $\mathrm{Na}^{+}-\mathrm{K}^{+}$ATPase Activity. After adding cold saline, the isolated myocardial tissues $(n=6)$ were immersed in cold PBS (weight $(\mathrm{g})$ : volume $(\mathrm{ml})=1: 9$ ). After homogenization, the solution was centrifuged at $2500 \mathrm{rpm}$ for $10 \mathrm{~min}$, and then, the supernatants were used to measure the $\mathrm{Na}^{+}$$\mathrm{K}^{+}$ATPase activity using a $\mathrm{Na}^{+}-\mathrm{K}^{+}$ATPase activity assay kit (Nanjing Jiancheng Institute of Bioengineering, Nanjing, China). The absorbance value of each sample was measured with a $4802 \mathrm{~S}$ ultraviolet/visible dual-beam spectrophotometer (Unico (Shanghai) Co., Ltd.) at $636 \mathrm{~nm}$, and each experiment was repeated three times.

2.10. $K^{+}$Flux. To study the effect of HF on myocardial tissue $\mathrm{K}^{+}$flux, noninvasive microtesting technology (NMT) (Younger USA LLC, Amherst, MA, USA) was used to measure the $\mathrm{K}^{+}$flux across the myocardial tissues. Prior to the measurement, C57BL/6 mice were anesthetized, and the heart was exposed in a clean ionic solution environment $(0.5 \mathrm{mM} \mathrm{KCl}$, $0.1 \mathrm{mM} \mathrm{CaCl}, 1 \mathrm{mM} \mathrm{NaCl}, 0.1 \mathrm{mM} \quad \mathrm{KH}_{2} \mathrm{PO}_{4}, 0.1 \mathrm{mM}$ $\mathrm{NaHCO}_{3}, 0.1 \mathrm{mM} \mathrm{Na} \mathrm{HPO}_{4}, 5.6 \mathrm{mM}$ glucose, and $\mathrm{pH} 7.2$ ). First, a tissue sample microsensor ( $\Phi 4.5 \pm 0.5 \mu \mathrm{m}$, XY-CGQ -01 , Younger, USA) was injected into a column of electrolyte solution $(100 \mathrm{mM} \mathrm{KCl})$ with a length of $1 \mathrm{~cm}$ at a distance of $1 \mathrm{~cm}$ from the tip. Then, a syringe was used to exert pressure on the flow sensor to gradually fill the tip of the flow sensor with electrolyte. A carrier glass electrode through a liquid ion exchanger (Liquid Ion-eXchange holder, LIX holder, XYLIX-01, Younger, USA) was injected into a liquid ion exchanger (Liquid Ion-eXchange, LIX, XY-SJ-K, Younger USA) with a length of $180 \mu \mathrm{m}$ into the tip, forming a $\mathrm{K}^{+}$flow sensor. After inserting the chlorinated silver wire from the back end of the $\mathrm{K}^{+}$flow sensor, the tip of the silver wire was immersed in the electrolyte and kept a certain distance from the tip of the $\mathrm{K}^{+}$flow sensor. After the sample testing was calibrated in the ion solution $(1 \mathrm{mM} \mathrm{KCl} / 0.1 \mathrm{mM} \mathrm{KCl}$, $0.1 \mathrm{mM} \quad \mathrm{CaCl}_{2}, 1 \mathrm{mM} \mathrm{NaCl}, 0.1 \mathrm{mM} \quad \mathrm{KH}_{2} \mathrm{PO}_{4}, 0.1 \mathrm{mM}$ $\mathrm{NaHCO}_{3}, 0.1 \mathrm{mM} \mathrm{Na} \mathrm{HPO}_{4}, 5.6 \mathrm{mM}$ glucose, and $\mathrm{pH} 7.2$ ), the $\mathrm{K}^{+}$flux determination was initiated. Fick's diffusion law formula was used to calculate the $\mathrm{K}^{+}$flux: $J$ (picomole 


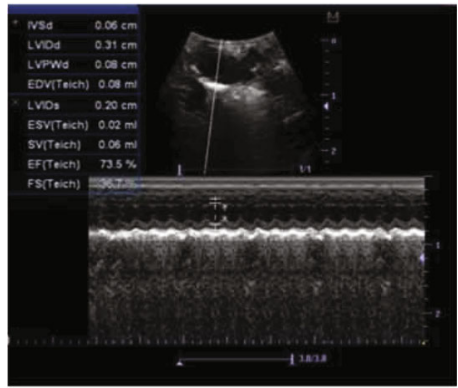

NC

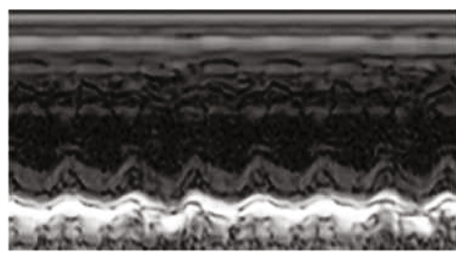

NC

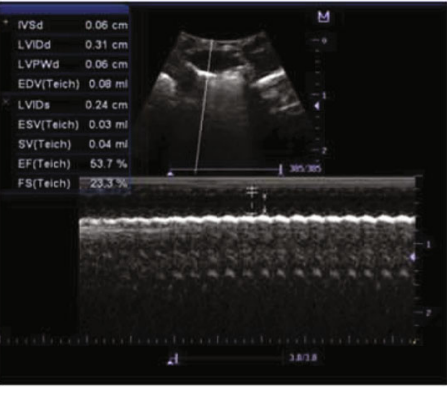

MOD

(a)

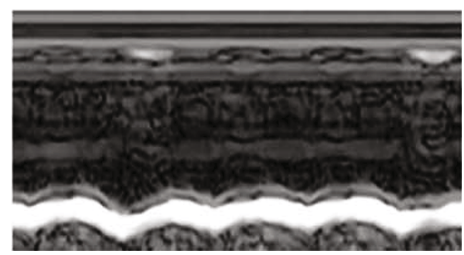

MOD

(b)

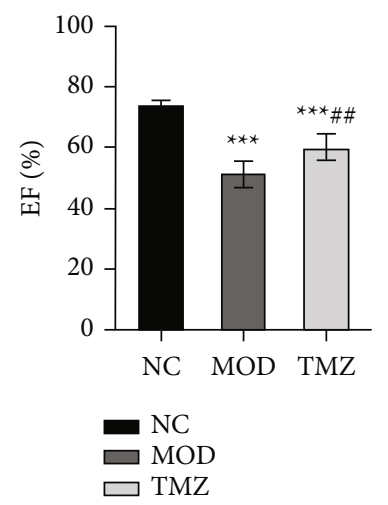

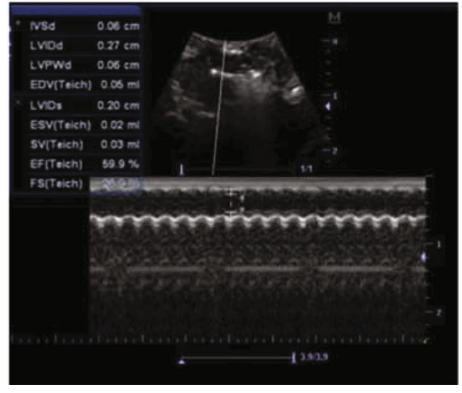

TMZ

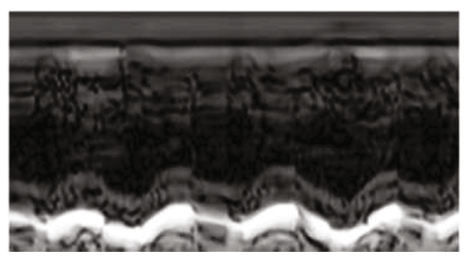

TMZ

(c)

FIGURE 1: Change in cardiac function in the NC, MOD, and TMZ groups. After modeling, decreased cardiac function was found in the MOD group. However, after TMZ treatment, cardiac function was restored $(\mathrm{a}, \mathrm{b})$. (c) A graph representing ejection fraction. ${ }^{* * *} P<$ 0.001 vs. NC group; ${ }^{\# \#} P<0.01$ vs. MOD group.

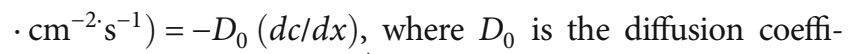
cient, $d c$ represents the $\mathrm{K}^{+}$concentration difference between the two test points, and $d x$ represents the distance between two test points $(5-35 \mu \mathrm{m})$.

2.11. Statistical Analysis. Each experiment was repeated three times, and data were presented as the mean \pm SD (standard deviation). The statistical analysis was performed using statistical software (SPSS for Windows, version 17.0, Chicago, USA) with one-way ANOVA followed by Tukey's multiple comparison test. $P<0.05$ was considered to be statistically significant.

\section{Results}

3.1. Effect of TMZ on Systolic Left Ventricular Function. After the relevant treatments for 6 weeks, the ejection fraction $(\mathrm{EF})$ of the mice in the MOD group was significantly reduced compared with that of the NC group $(51.36 \pm 3 \%$ vs. 73.59
TABLE 2: Determination of BNP level $(n=8)$.

\begin{tabular}{lc}
\hline Groups & BNP level $(\mathrm{pg} / \mathrm{ml})$ \\
\hline NC & $158.673 \pm 65.867$ \\
MOD & $485.742 \pm 124.613^{* * *}$ \\
TMZ & $343.39 \pm 55.393^{* * \# \#}$ \\
\hline${ }^{* *} P<0.01$ and ${ }^{* * *} P<0.001$ vs. NC group. ${ }^{\# *} P<0.01$ vs. MOD group.
\end{tabular}

$\pm 2 \%,{ }^{* *} P<0.001$, Figure 1$)$. However, after TMZ treatment, we noted that the EF of the mice in the TMZ group was apparently restored compared with that of the MOD group (60.34 $\pm 4 \%$ vs. $51.36 \pm 3 \%,{ }^{\# \#} P<0.01$, Figure 1$)$, indicating the good therapeutic effect of TMZ on HF.

3.2. BNP Level. The comparison of BNP levels in serum between the MOD and NC groups showed that the BNP level in the MOD group was significantly higher than that 


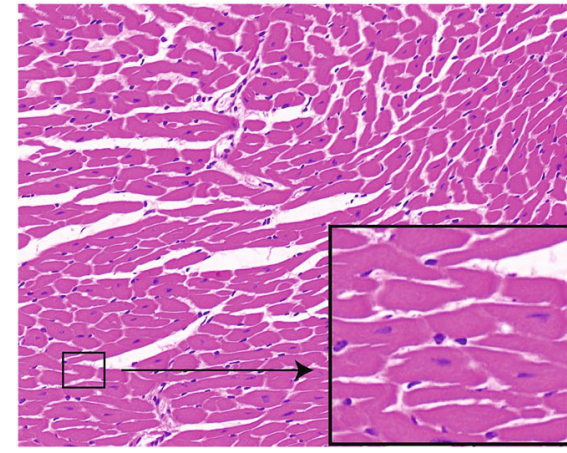

(a)

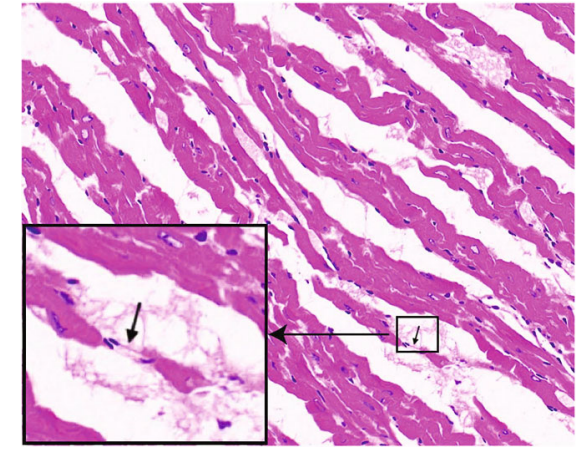

(b)

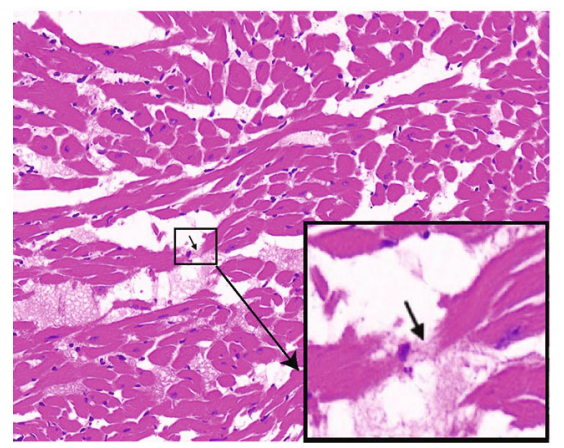

(c)

FIGURE 2: Histopathological characterization of the myocardial tissues of C57BL/6 mice in each group. After different treatments, the mice in each group were sacrificed, and the myocardial tissues were isolated and sectioned. After staining with hematoxylin and eosin (H\&E) solution, the sections were observed under a microscope. Magnification: 200x. (a) Normal control group, (b) model group, and (c) TMZ group $(10 \mathrm{mg} / \mathrm{kg} / \mathrm{d})$.

in the NC group, and the difference was statistically significant (Table $2,{ }^{* * *} P<0.001$ ), indicating that the HF model of mice was successfully established. We also noted that after TMZ treatment, the BNP level decreased significantly compared with that of the MOD group (Table $2,{ }^{\# \#} P<0.01$ ).

\subsection{Pathological Change in Myocardial Tissues. Histopathol-} ogical examination showed that the myocardial tissues of the C57BL/6 mice in the NC group were in good alignment, the myocardial fiber morphology and structure were normal, the boundaries were clear, the arrangement was regular, and there was no obvious abnormality in the interstitium (Figure 2(a)). However, a large amount of myocardial fiber lysis and fracture (black arrow), a small amount of myocardial fiber vacuole degeneration, circular vacuoles of various sizes, and eosinophilic substances were observed in the tissues from the MOD group (Figure 2(b)). Meanwhile, a small amount of myocardial fibrillation (black arrow) and eosinophilic substance exudation were observed locally in the myocardial tissue of the mice in the TMZ group (Figure 2(c)).

3.4. Change in Ultrastructure of Myocardial Mitochondria. As shown in Figure 3, the mitochondria of the left ventricular myocardium in the NC group were well proportioned, well balanced in size, and regularly arranged. The mitochondrial cristae were clear and complete, the membranes were intact, sarcomeres were arranged neatly, horizontal stripes were clear, bright and dark bands were clearly visible (Figure 3(a), arrows), and the structure of each part was complete. In contrast, mitochondria in the MOD group varied in size, with more than $1 \mu \mathrm{m}$ in transverse diameter, and there was also mitochondrial swelling and hypertrophy, displacement and aggregation with loss of mitochondrial membrane, mitochondrial crista dissolution and breakage, and disordered or missing muscle fiber arrangement (Figure 3(b), arrows). After TMZ treatment, there were myocardial mitochondrial edema vacuole-like changes, some mitochondrial cristae were blurred or even broken, and the arrangement of muscle fibers was disordered, but to a lighter extent than in the MOD group (Figure 3(c), arrows).

3.5. Change of ATP Level in Myocardial Tissues. To study the changes in ATP content in myocardial tissues after different treatments, we measured the ATP level in myocardial tissues in the NC, MOD, and TMZ groups. As shown in Figure 4, the ATP content in the MOD group was significantly reduced compared with that in the NC group $\left({ }^{* * *} P<0.001\right)$. At the same time, it was also found that the ATP content in myocardial tissues in the TMZ group was apparently higher than that in the MOD group $\left({ }^{\# \#} P<0.01\right.$, Figure 4$)$. Nevertheless, the ATP content in the TMZ group was lower than that in the NC group $\left({ }^{* * *} P<0.001\right.$, Figure 4$)$.

3.6. $\mathrm{Na}^{+}-\mathrm{K}^{+}$ATPase Expression. To explore the effect of different treatments on the expression of $\mathrm{Na}^{+}-\mathrm{K}^{+}$ATPase in the myocardial tissue of C57BL/6 mice, we measured $\mathrm{Na}^{+}-\mathrm{K}^{+}$ 


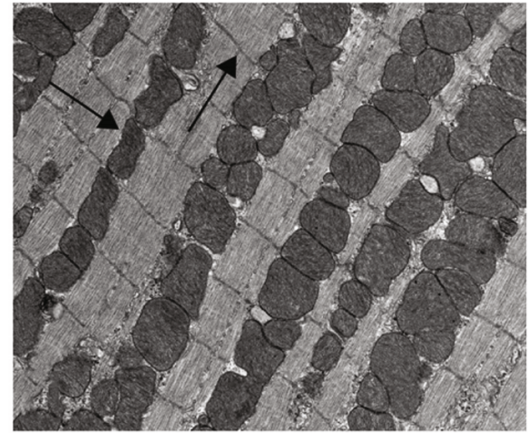

(a)

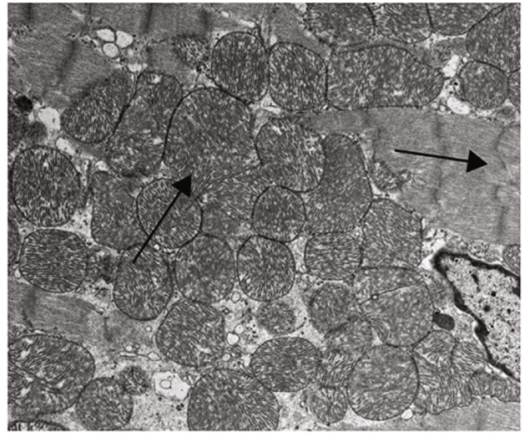

(b)

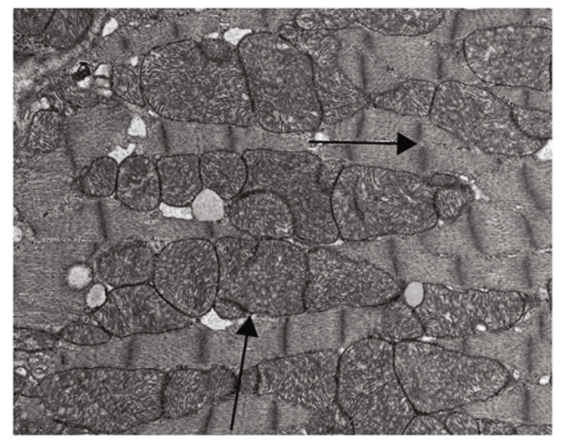

(c)

FIGURE 3: Mitochondrial ultrastructure of cardiomyocytes: (a) NC group; (b) MOD group; (c) TMZ group.

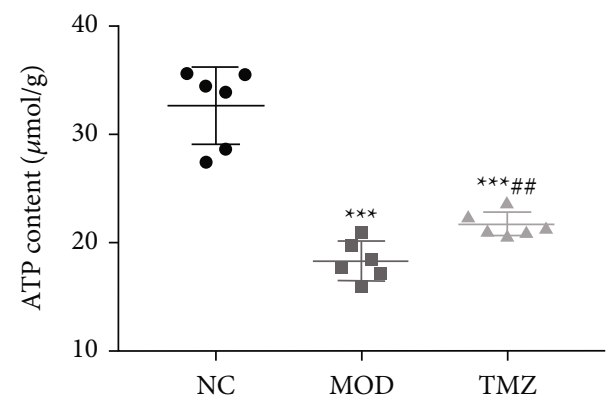

FIgURE 4: Determination of ATP contents in myocardial tissues in the NC, MOD, and TMZ groups. The results showed that the ATP content of MOD mice was lower than that of the NC group. However, after TMZ treatment, the ATP content in the myocardial tissues was higher than that in the MOD group. Compared to the NC group, ${ }^{* *} P<0.001$; compared to the MOD group, ${ }^{\# \#} P<0.01 . n=6$.

ATPase expression at the mRNA and protein levels in the myocardial tissues of the NC, MOD, and TMZ groups. The results showed that the $\mathrm{Na}^{+}-\mathrm{K}^{+}$ATPase mRNA level in myocardial tissues in the MOD group was significantly lower than that in the NC group $\left({ }^{* *} P<0.001\right.$, Figure $\left.5(\mathrm{a})\right)$. Similarly, the $\mathrm{Na}^{+}-\mathrm{K}^{+}$ATPase protein level in the myocardial tissues in the MOD group was also significantly lower than that in the NC group $\left({ }^{* *} P<0.001\right.$, Figure 5(b)). In contrast, TMZ treatment markedly elevated $\mathrm{Na}^{+}-\mathrm{K}^{+}$ATPase expression at the mRNA and protein levels compared to the MOD group (\#\# $P<0.001$ and ${ }^{\#} P<0.05$, Figures 5(a) and 5(b)).
3.7. Changes in $\mathrm{Na}^{+}-\mathrm{K}^{+}$ATPase Activity. As shown in Figure 6 , the results show that compared with that of $\mathrm{NC}$ mice, the $\mathrm{Na}^{+}-\mathrm{K}^{+}$ATPase activity in the MOD group was significantly reduced $\left({ }^{* *} P<0.001\right.$, Figure 6$)$. However, TMZ treatment apparently elevated $\mathrm{Na}^{+}-\mathrm{K}^{+}$ATPase activity compared with that of the MOD group $\left({ }^{\#} P<0.05\right.$, Figure 6$)$, indicating that TMZ treatment can efficiently enhance the activity of $\mathrm{Na}^{+}-\mathrm{K}^{+}$ATPase.

3.8. Measurements of $\mathrm{K}^{+}$Flux. To explore the influence of various treatments on $\mathrm{K}^{+}$flux in myocardiocytes, we determined the real-time $\mathrm{K}^{+}$flux using NMT. As shown in Figure $7, \mathrm{~K}^{+}$flux across the myocardial tissue from normal mice shows an outflow trend and is at a high level. In contrast, the $\mathrm{K}^{+}$flux in the MOD group was near the static state, indicating seriously damaged myocardial function. However, after TMZ treatment, we noted that the $\mathrm{K}^{+}$flux was apparently restored, indicating enhanced myocardial function.

\section{Discussion}

As a rapidly growing public health issue and a clinically complex chronic disease, HF seriously affects the quality of life of patients $[25,26]$. In recent years, the regulation of cardiac energy metabolism by reducing fatty acid oxidation and/or increasing glucose oxidation has been a new way to treat HF. TMZ is a metabolic regulator that is widely used in the treatment of stable angina pectoris, and there is a relatively large amount of evidence demonstrating that it can be used to treat HF [27]. Studies have shown that TMZ exerts its anti-ischemic effect by regulating the metabolism of myocardial tissue 


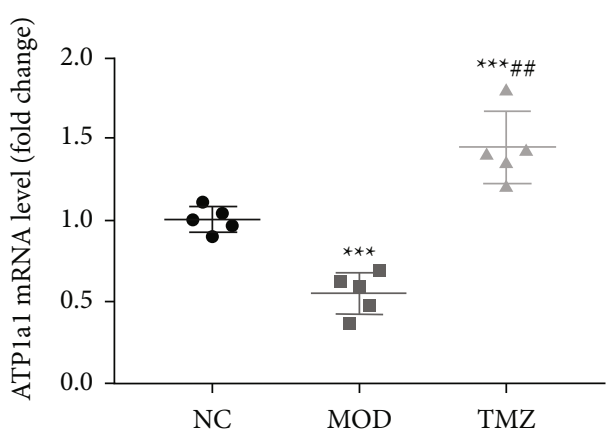

(a)

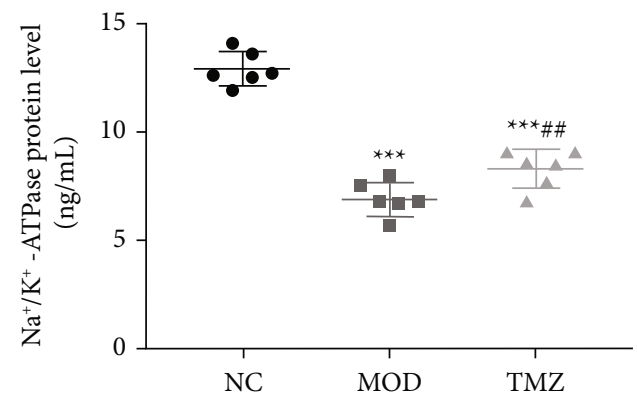

(b)

Figure 5: Determination of the expression of ATP $1 \alpha 1$ at the mRNA and protein levels in myocardial tissues in C57BL/6 mice after different treatments. After relevant treatments, ATP $1 \alpha 1$ mRNA and protein levels were measured by Q-PCR and ELISA, respectively. The results show that the expression of ATP1 $\alpha 1$ in the myocardium in the MOD group was significantly lower than that in the NC group. After TMZ treatment, the $\mathrm{Na}^{+}-\mathrm{K}^{+}$ATPase protein level was significantly elevated compared to that in the MOD group. Compared to the NC group, ${ }^{* *} P<0.01$ and ${ }^{* * *} P<0.001$; compared to the MOD group, ${ }^{\#} P<0.05$ and ${ }^{\# \# \#} P<0.001 . n=5$ for the determination of ATP $1 \alpha 1$ mRNA levels, $n=6$ for the determination of $\mathrm{Na}^{+}-\mathrm{K}^{+}$ATPase protein levels.

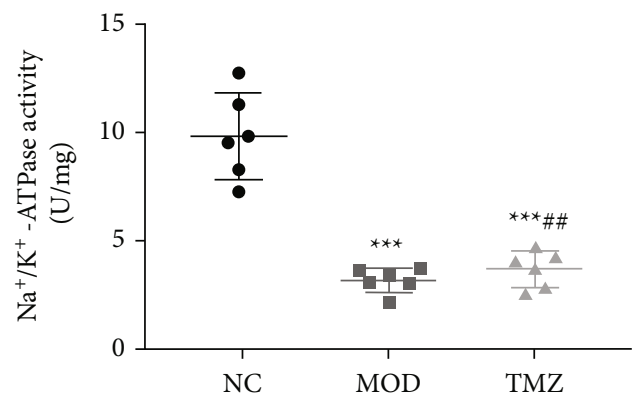

Figure 6: Determination of $\mathrm{Na}^{+}-\mathrm{K}^{+}$ATPase activities in the myocardial tissues of C57BL/6 mice after different treatments. An HF mouse model was induced by doxorubicin administration, and the mice received different treatments for 6 weeks. At the indicated time, the mice were sacrificed after anesthesia, and myocardial tissues were isolated, ground under liquid nitrogen, and centrifuged at $2500 \mathrm{rpm}$ for $10 \mathrm{~min}$. Then, the supernatants were collected to measure $\mathrm{Na}^{+}-\mathrm{K}^{+}$ATPase activity. Compared to the NC group, ${ }^{* * *} P$ $<0.001$; compared to the MOD group, ${ }^{\#} P<0.05 . n=6$.

mitochondria without changing hemodynamic function and has no effect on coronary flow, contractility, blood pressure, or heart rate [28]. Current research shows that TMZ can inhibit fatty acid oxidation and increase glucose oxidation, thereby producing ATP and consuming less oxygen [29]. In addition, Chen et al. showed that TMZ can reduce LPSinduced cardiomyocyte apoptosis and cardiac dysfunction by promoting the recruitment of neutrophils to cardiac tissue through CXCR2 [30]. Moreover, TMZ can also protect against $\mathrm{Ca}^{2+}$ overload and $\mathrm{Ca}^{2+}$ release in arrhythmia, thus maintaining sufficient contractility of HF myocardium [31], improving antioxidant levels, decreasing oxidative stress, and reducing plasma BNP levels [32]. To investigate the protective effect of TMZ on the myocardium in HF mice and the underlying mechanism, we established a doxorubicin-induced HF mouse model. Our results show that TMZ treatment effectively reduced the BNP level in the serum of HF mice, which is released from ventricular myocytes due to myocardial stress, such as myocardial infarction and HF. Histopathological examination showed that normal mouse myocardial tissues were arranged neatly and structurally intact, while the myocardium in HF mice was disorderly arranged and severely damaged, and there were multiple myocardial dissolutions and myofilament ruptures. These results are consistent with the study by Al-Harthi et al. [33].

The high energy demand of the heart is mainly met by mitochondrial oxidation of fatty acids and glucose [34]. Mitochondrial oxidative phosphorylation uses fatty acids, glucose, lactic acid, and ketone bodies as the main substrates to produce ATP [35]. However, the glucose oxidation metabolism of heart mitochondria will be reduced in HF, which will lead to insufficient energy of myocardial tissue. Myocardial energy metabolism disorder is one of the important causes of HF $[36,37]$, and mitochondrial dysfunction is the driving force involved in the imbalance of myocardial energy supply and demand [38], which ultimately causes a lack of ATP in myocardial tissue and impaired myocardial contractility [39]. The free energy produced by ATP hydrolysis $(\triangle \mathrm{G} \sim \mathrm{ATP})$ is an important indicator of myocardial energy. If myocardial cells are in a state of ischemia or hypoxia, $\Delta \mathrm{G} \sim \mathrm{ATP}$ will decrease, and cardiac contractility will be weakened, eventually leading to HF [40]. Under normal physiological conditions, the oxidative phosphorylation of mitochondria in cells can produce adequate ATP [41], and its intracellular function is mainly to store and transmit chemical energy so that various life activities of the cell can obtain sufficient energy support. It is well known that the heart is an organ with high oxygen consumption, and myocardial tissue needs ATP hydrolysis to generate a large amount of energy to ensure the normal operation of its own electromechanical activities. Considering that $\mathrm{Na}^{+}-\mathrm{K}^{+}$ ATPase requires energy from ATP hydrolysis to maintain normal physiological functions, it is essential for the electrical excitability of cells to maintain the balance of cell membrane potential. Thus, energy metabolism disorders will seriously affect the activity of $\mathrm{Na}^{+}-\mathrm{K}^{+}$ATPase. When the homeostasis of ions within the cell is destroyed, cell function 


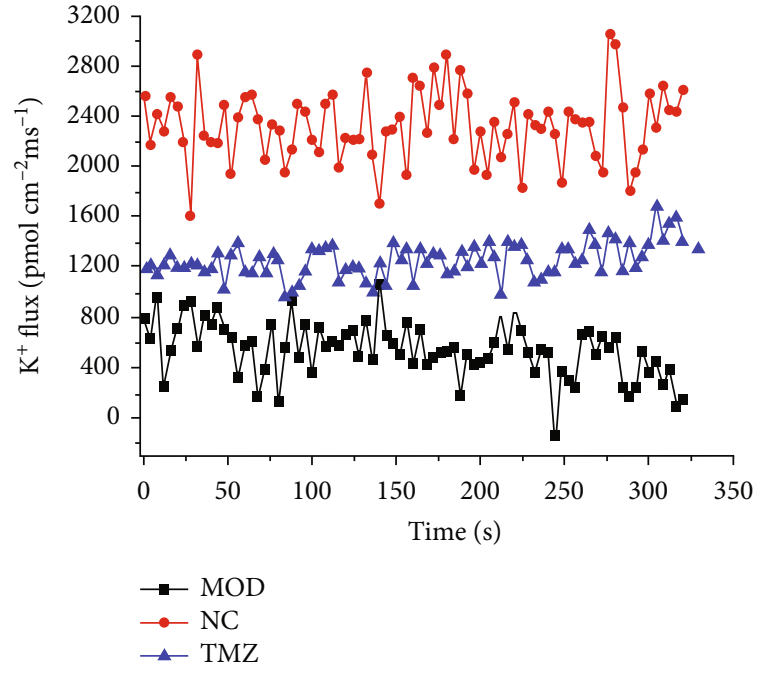

(a)

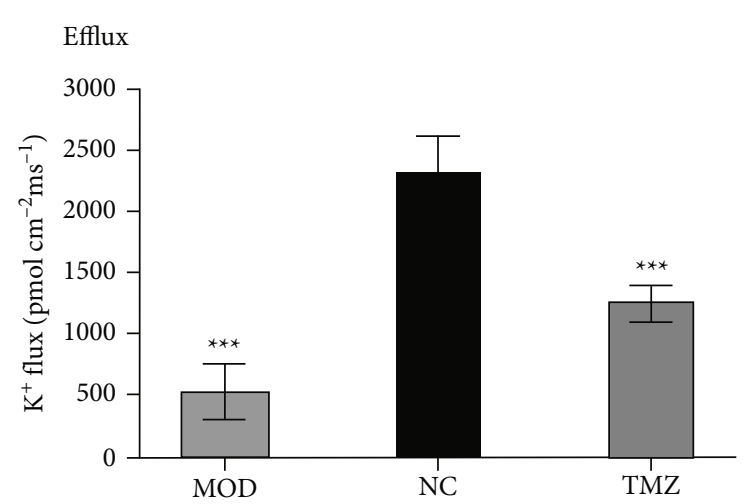

(b)

Figure 7: Measurement of $\mathrm{K}^{+}$flux across the myocardial tissue in C57BL/6 mice in the NC, MOD, and TMZ groups. After relevant treatments, C57BL/6 mice were first anesthetized, the myocardial tissue was exposed, and then NMT was used to measure the real-time $\mathrm{K}^{+}$flux across the myocardial tissue (a). Histogram analysis shows the trend of $\mathrm{K}^{+}$flux measured by the NMT technique in C57BL/6 mice in the TMZ group (b). ${ }^{* * *} P<0.001$ vs. NC group.

will be impaired, and eventually, HF develops. Panagia et al. have shown that the inhibition of acute reversal of mitochondrial ATP production can improve systolic dysfunction in metabolic HF [42]. In our study, we noted that the myocardial tissues in mice with HF exhibited decreased ATP production, indicating that HF could damage the capacity of ATP production in myocardial tissues and thus lead to dysfunction of ATP metabolism. Treatment with TMZ can enhance ATP synthesis, prevent transmission obstacles, increase ATP generation, improve myocardial energy metabolism to a certain extent, and finally rehabilitate heart function. TMZ acts as an inhibitor of free fatty acid oxidation, selectively inhibits long-chain 3-ketoacyl-CoA thiolase, and directly stimulates pyruvate dehydrogenase, which converts cardiac energy metabolism from fatty acid oxidation to glucose oxidation to preserve the level of ATP necessary within the cells of the myocardium [43].

Moreover, we also noted that TMZ can increase the expression of ATP $1 \alpha 1$ and stimulate the activity of $\mathrm{Na}^{+}-\mathrm{K}^{+}$ATPase to a certain extent compared with HF mice. $\mathrm{Na}^{+}-\mathrm{K}^{+}$ATPase is a P-type ion translocating adenosine triphosphatase that can couple ATP hydrolysis with the transport of three $\mathrm{Na}^{+}$ions out and two $\mathrm{K}^{+}$ions into cells to maintain the penetration and ion balance between the internal and external environments of the cells [44-46]. The enzyme contains two main subunits ( $\alpha$ and $\beta$ ), of which $\alpha$ subunits exist in the form of four subtypes ( $\alpha 1-\alpha 4)$, encoded by four different genes ATP1 $\alpha 1-4$ $[47,48]$. Dostanic et al. found that ATP $1 \alpha 1$ isoforms can regulate cardiac contractility. At high concentrations of ouabain, the activity of ATP $1 \alpha 1$ subtypes is significantly reduced, HF occurs, and ATP1 $\alpha 1$ subtypes account for most of the mouse heart [49]. Therefore, inhibition of $\mathrm{Na}^{+}-\mathrm{K}^{+}$ATPase activity can lead to HF. The activity of $\mathrm{Na}^{+}-\mathrm{K}^{+}$ATPase in the myocardial tissue of the MOD group was reduced, and the expression of ATP $1 \alpha 1$ was inhibited, which was consistent with our exper- imental results. Correll et al. found that the removal of $\mathrm{Na}^{+}$ from the cytoplasm of cardiomyocytes is mainly accomplished by $\mathrm{Na}^{+}-\mathrm{K}^{+}$ATPase- $\alpha 1$, which accounts for $88 \%$ of cardiac $\mathrm{Na}^{+}-$ $\mathrm{K}^{+}$ATPase activity [50]. Moreover, a large amount of evidence shows that $\mathrm{Na}^{+}-\mathrm{K}^{+}$ATPase can regulate cardiac contractility. As a ubiquitous subtype, the $\alpha 1$ subtype is dominant in cardiomyocytes with pumping and signaling functions and usually changes in hypertrophic and failing hearts [51, 52]. Furthermore, $\mathrm{Na}^{+}-\mathrm{K}^{+}$ATPase is also the only known receptor for cardiotonic steroids (such as ouabain) [53]. It has been reported that digitalis can be used to treat HF because it can inhibit the pumping function of $\mathrm{Na}^{+}-\mathrm{K}^{+}$ATPase and stimulate the signal conduction function [54]. $\mathrm{Na}^{+}-\mathrm{K}^{+}$ATPase is also an important mediator of vasculature tension and contractility, and its abnormal expression can induce myocardial cell death and cardiac dysfunction, possibly leading to myocardial expansion and HF [55].

Hisatome et al. found that TMZ has a slight inhibitory effect on $\mathrm{Na}^{+}-\mathrm{K}^{+}$ATPase [56]. In contrast, this study found that the $\mathrm{Na}^{+}-\mathrm{K}^{+}$ATPase activity of mice treated with TMZ was higher than that of the HF group. We believe that the difference in the results is due to the more severely inhibited $\mathrm{Na}^{+}-\mathrm{K}^{+}$ATPase activity in mice with HF. Moreover, growing evidence shows that $\mathrm{Na}^{+}-\mathrm{K}^{+}$ATPase is closely related to cardiac electrophysiology and myocardial contractility. In fact, changes in $\mathrm{Na}^{+}-\mathrm{K}^{+}$ATPase activity can affect skeletal muscle absorption or the release of $\mathrm{K}^{+}$[57]. During muscle fiber excitement, the action potential is associated with a significant increase in $\mathrm{Na}^{+}$influx and $\mathrm{K}^{+}$efflux [58]. Under normal physiological conditions, the action potential consists of two stages: (1) depolarization caused by the increase in $\mathrm{Na}^{+}$influx and (2) repolarization caused by the increase in $\mathrm{K}^{+}$efflux through the voltage-dependent potassium channel $(\mathrm{Kv})$ [59]. Every normal heartbeat is generated by an action potential (AP) wave, which travels from the atrium to the 
ventricle, causing the heart to contract and eject blood [60]. To date, a large number of studies have shown that the current of cardiac repolarization will produce important changes when HF occurs, and the downregulation of multiple $\mathrm{K}^{+}$channel currents causes delays in repolarization and prolongs the duration of action potentials [61-63]. In this study, we found that the $\mathrm{K}^{+}$flux rate in $\mathrm{HF}$ mouse cardiomyocytes was much lower than that in normal mouse cardiomyocytes. We speculate that $\mathrm{K}^{+}$homeostasis is crucial for maintaining normal myocardial function. The status of $\mathrm{K}^{+}$homeostasis in myocardial tissue in HF mice was destroyed, and TMZ treatment efficiently contributed to restoring the balance of $\mathrm{K}^{+}$flux to maintain the action potential of the heart, thereby improving cardiovascular function.

\section{Conclusion}

In summary, our results indicate that TMZ can efficiently increase the expression of ATP $1 \alpha 1$ in myocardial tissues in mice with $\mathrm{HF}$, enhance the activity and production of $\mathrm{Na}^{+}$$\mathrm{K}^{+}$ATPase, elevate the content of ATP, and efficiently restore and maintain the balance of $\mathrm{K}^{+}$homeostasis within myocardial cells, thereby improving the energy metabolism of the heart and rehabilitating the balance of the myocardial microenvironment. Our study provides a new theoretical basis for the clinical application of TMZ in the treatment of HF.

\section{Data Availability}

The data sets used and/or analyzed in the current research can be obtained from the corresponding authors according to reasonable requirements.

\section{Ethical Approval}

The current experiment has been approved by the Experimental Animal Ethics Committee of the Affiliated Hospital of Shandong University of Traditional Chinese Medicine (AWE-2019-01). All experiments were designed to reduce the discomfort and stress of the animals. Meanwhile, the whole experiments were strictly abode by the principles of care and use of laboratory animals and the "Guiding Opinions on Treating Laboratory animals" issued by the Ministry of Science and Technology of the People's Republic of China (2006).

\section{Conflicts of Interest}

The authors declare that they have no conflicts of interest.

\section{Authors' Contributions}

Yitao Xue and Dadong Guo participated in research design. Kaijing Yang, Miao Yu, Wenwen Liu, Kaiming Chen, Nannan Chen, and Linlin Song conducted experiments. Yan Li, Xijin Wei, and Huachen Jiao contributed new reagents or analytic tools. Yang Sun and Ting Yu performed data analysis. Kaijing Yang, Yitao Xue, and Dadong Guo wrote or contributed to the writing of the manuscript. Kaijing Yang and Yitao Xue contributed equally to this work.

\section{Acknowledgments}

This study was supported by the National Natural Science Foundation of China (Nos. 81774247 and 81804045).

\section{References}

[1] D. Tomasoni, M. Adamo, C. M. Lombardi, and M. Metra, "Highlights in heart failure," ESC heart failure, vol. 6, no. 6, pp. 1105-1127, 2019.

[2] F. Orso, G. Fabbri, and A. P. Maggioni, "Epidemiology of heart failure," Handbook of Experimental Pharmacology, vol. 243, pp. 15-33, 2017.

[3] V. W. Dolinsky, L. K. Cole, G. C. Sparagna, and G. M. Hatch, "Cardiac mitochondrial energy metabolism in heart failure: role of cardiolipin and sirtuins," Biochimica et Biophysica Acta, vol. 1861, no. 10, pp. 1544-1554, 2016.

[4] J. J. Dalal and S. Mishra, "Modulation of myocardial energetics: an important category of agents in the multimodal treatment of coronary artery disease and heart failure," Indian Heart Journal, vol. 69, no. 3, pp. 393-401, 2017.

[5] N. Fillmore, J. Mori, and G. D. Lopaschuk, "Mitochondrial fatty acid oxidation alterations in heart failure, ischaemic heart disease and diabetic cardiomyopathy," British Journal of Pharmacology, vol. 171, no. 8, pp. 2080-2090, 2014.

[6] W. Wang and G. D. Lopaschuk, "Metabolic therapy for the treatment of ischemic heart disease: reality and expectations," Expert Review of Cardiovascular Therapy, vol. 5, no. 6, pp. 1123-1134, 2007.

[7] Y. M. Lopatin, G. M. Rosano, G. Fragasso et al., "Rationale and benefits of trimetazidine by acting on cardiac metabolism in heart failure," International Journal of Cardiology, vol. 203, pp. 909-915, 2016.

[8] H. Li, Z. Ma, Y. Zhai et al., "Trimetazidine ameliorates myocardial metabolic remodeling in isoproterenol-induced rats through regulating ketone body metabolism via activating AMPK and PPAR $\alpha$, Frontiers in Pharmacology, vol. 11, p. $1255,2020$.

[9] B. Zhou and R. Tian, "Mitochondrial dysfunction in pathophysiology of heart failure," The Journal of Clinical Investigation, vol. 128, no. 9, pp. 3716-3726, 2018.

[10] M. J. Shattock, M. Ottolia, D. M. Bers et al., " $\mathrm{Na}^{+} / \mathrm{Ca}^{+}$ exchange and $\mathrm{Na}^{+} / \mathrm{K}^{+}$-ATPase in the heart," The Journal of Physiology, vol. 593, no. 6, pp. 1361-1382, 2015.

[11] C. Chen, W. Bu, H. Ding et al., "Cytotoxic effect of zinc oxide nanoparticles on murine photoreceptor cellsviapotassium channel block and $\mathrm{Na}^{+} / \mathrm{K}^{+}$-ATPase inhibition," Cell Proliferation, vol. 50, no. 3, article e12339, 2017.

[12] Z. Bastug-Özel, P. T. Wright, A. E. Kraft et al., "Heart failure leads to altered $\beta_{2}$-adrenoceptor/cyclic adenosine monophosphate dynamics in the sarcolemmal phospholemman $/ \mathrm{Na}, \mathrm{K}$ ATPase microdomain," Cardiovascular research, vol. 115, no. 3, pp. 546-555, 2019.

[13] L. Zhang, C. Staehr, F. Zeng, E. V. Bouzinova, and V. V. Matchkov, "The Na,K-ATPase in vascular smooth muscle cells," Current Topics in Membranes, vol. 83, pp. 151-175, 2019.

[14] K. C. Yang and J. M. Nerbonne, "Mechanisms contributing to myocardial potassium channel diversity, regulation and remodeling," Trends in Cardiovascular Medicine, vol. 26, no. 3, pp. 209-218, 2016. 
[15] B. Trenor, K. Cardona, J. F. Gomez et al., "Simulation and mechanistic investigation of the arrhythmogenic role of the late sodium current in human heart failure," PLoS One, vol. 7, no. 3, article e32659, 2012.

[16] B. Hegyi, J. Bossuyt, K. S. Ginsburg et al., "Altered repolarization reserve in failing rabbit ventricular myocytes: calcium and $\beta$-adrenergic effects on delayed- and inward-rectifier potassium currents," Circulation. Arrhythmia and Electrophysiology, vol. 11, no. 2, article e005852, 2018.

[17] J. N. Weiss, "Palpitations, potassium and the pump," The Journal of Physiology, vol. 593, no. 6, pp. 1387-1388, 2015.

[18] Y. Pirahanchi, R. Jessu, and N. R. Aeddula, "Physiology, Sodium Potassium Pump," in StatPearls, StatPearls Publishing, Treasure Island (FL), 2020.

[19] H. L. Wang, X. H. Cui, H. L. Yu, R. Wu, X. Xu, and J. P. Gao, "Synergistic effects of polydatin and vitamin $\mathrm{C}$ in inhibiting cardiotoxicity induced by doxorubicin in rats," Fundamental \& Clinical Pharmacology, vol. 31, no. 3, pp. 280-291, 2017.

[20] M. Mewes, J. Nedele, K. Schelleckes et al., "Salt-induced $\mathrm{Na}^{+}$/ $\mathrm{K}^{+}$-ATPase- $\alpha / \beta$ expression involves soluble adenylyl cyclase in endothelial cells," Pflügers Archiv, vol. 469, no. 10, pp. 1401-1412, 2017.

[21] Y. Yang, N. Li, T. Chen et al., "Trimetazidine ameliorates sunitinib-induced cardiotoxicity in mice via the AMPK/ mTOR/autophagy pathway," Pharmaceutical Biology, vol. 57, no. 1, pp. 625-631, 2019.

[22] S. Jatain, A. Kapoor, A. Sinha et al., "Metabolic manipulation in dilated cardiomyopathy: assessing the role of trimetazidine," Indian Heart Journal, vol. 68, no. 6, pp. 803-808, 2016.

[23] G. M. Rosano and C. Vitale, "Metabolic modulation of cardiac metabolism in heart failure," Cardiac Failure Review, vol. 4, no. 2, pp. 99-103, 2018.

[24] N. Siveski-Iliskovic, N. Kaul, and P. K. Singal, "Probucol promotes endogenous antioxidants and provides protection against adriamycin-induced cardiomyopathy in rats," Circulation, vol. 89, no. 6, pp. 2829-2835, 1994.

[25] F. Koehler, K. Koehler, O. Deckwart et al., “Telemedical Interventional Management in Heart Failure II (TIM-HF2), a randomised, controlled trial investigating the impact of telemedicine on unplanned cardiovascular hospitalisations and mortality in heart failure patients: study design and description of the intervention," European Journal of Heart Failure, vol. 20, no. 10, pp. 1485-1493, 2018.

[26] B. Ziaeian and G. C. Fonarow, "Epidemiology and aetiology of heart failure," Nature Reviews. Cardiology, vol. 13, no. 6, pp. 368-378, 2016.

[27] A. Steggall, I. R. Mordi, and C. C. Lang, "Targeting metabolic modulation and mitochondrial dysfunction in the treatment of heart failure," Diseases, vol. 5, no. 2, p. 14, 2017.

[28] C. A. Dézsi, "Trimetazidine in practice: review of the clinical and experimental evidence," American Journal of Therapeutics, vol. 23, no. 3, pp. e871-e879, 2016.

[29] G. Fragasso, G. Perseghin, F. De Cobelli et al., "Effects of metabolic modulation by trimetazidine on left ventricular function and phosphocreatine/adenosine triphosphate ratio in patients with heart failure," European Heart Journal, vol. 27, no. 8, pp. 942-948, 2006.

[30] J. Chen, B. Wang, J. Lai et al., "Trimetazidine attenuates cardiac dysfunction in endotoxemia and sepsis by promoting neutrophil migration," Frontiers in Immunology, vol. 9, p. $2015,2018$.
[31] E. N. Dedkova, L. K. Seidlmayer, and L. A. Blatter, "Mitochondria-mediated cardioprotection by trimetazidine in rabbit heart failure," Journal of Molecular and Cellular Cardiology, vol. 59, pp. 41-54, 2013.

[32] E. Bayram, C. Atalay, H. Kocatürk, and O. Yücel, "Effects of trimetazidine on lipid peroxidation, antioxidant enzyme activities and plasma brain natriuretic peptide levels in patients with chronic cor pulmonale," The Journal of International Medical Research, vol. 33, no. 6, pp. 612-619, 2005.

[33] S. E. Al-Harthi, O. M. Alarabi, W. S. Ramadan et al., "Amelioration of doxorubicin-induced cardiotoxicity by resveratrol," Molecular Medicine Reports, vol. 10, no. 3, pp. 1455-1460, 2014.

[34] G. D. Lopaschuk, Q. G. Karwi, K. L. Ho, S. Pherwani, and E. B. Ketema, "Ketone metabolism in the failing heart," Biochimica et Biophysica Acta - Molecular and Cell Biology of Lipids, vol. 1865, no. 12, article 158813, 2020.

[35] T. Kashihara and J. Sadoshima, "Role of YAP/TAZ in energy metabolism in the heart," Journal of Cardiovascular Pharmacology, vol. 74, no. 6, pp. 483-490, 2019.

[36] S. Neubauer, "The failing heart — an engine out of fuel," The New England Journal of Medicine, vol. 356, no. 11, pp. 11401151, 2007.

[37] A. Fukushima, K. Milner, A. Gupta, and G. D. Lopaschuk, "Myocardial energy substrate metabolism in heart failure: from pathways to therapeutic targets," Current Pharmaceutical Design, vol. 21, no. 25, pp. 3654-3664, 2015.

[38] H. N. Sabbah, "Targeting the mitochondria in heart failure: a translational perspective," JACC: Basic to Translational Science, vol. 5, no. 1, pp. 88-106, 2020.

[39] T. Doenst, T. D. Nguyen, and E. D. Abel, "Cardiac metabolism in heart failure: implications beyond ATP production," Circulation Research, vol. 113, no. 6, pp. 709-724, 2013.

[40] K. W. Saupe, M. Spindler, J. C. Hopkins, W. Shen, and J. S. Ingwall, "Kinetic, thermodynamic, and developmental consequences of deleting creatine kinase isoenzymes from the heart:" The Journal of Biological Chemistry, vol. 275, no. 26, pp. 19742-19746, 2000.

[41] L. C. Crowley, M. E. Christensen, and N. J. Waterhouse, "Measuring mitochondrial transmembrane potential by TMRE staining," Cold Spring Harbor Protocols, vol. 2016, no. 12, 2016.

[42] M. Panagia, H. He, T. Baka et al., "Increasing mitochondrial ATP synthesis with butyrate normalizes ADP and contractile function in metabolic heart disease," NMR in Biomedicine, vol. 33, no. 5, article e4258, 2020.

[43] Y. Zhang, X. J. Ma, and D. Z. Shi, "Effect of trimetazidine in patients undergoing percutaneous coronary intervention: a meta-analysis," PLoS One, vol. 10, no. 9, article e0137775, 2015.

[44] C. Toyoshima, R. Kanai, and F. Cornelius, "First crystal structures of $\mathrm{Na}^{+}, \mathrm{K}^{+}$-ATPase: new light on the oldest ion pump," Structure, vol. 19, no. 12, pp. 1732-1738, 2011.

[45] M. A. Placenti, S. B. Kaufman, F. L. González Flecha, and R. M. González Lebrero, "Unexpected effects of $\mathrm{K}^{+}$and adenosine triphosphate on the thermal stability of $\mathrm{Na}^{+}, \mathrm{K}^{+}$-ATPase," The Journal of Physical Chemistry. B, vol. 121, no. 19, pp. 4949-4957, 2017.

[46] D. R. Câmara, J. P. Kastelic, and J. C. Thundathil, "Role of the $\mathrm{Na}^{+} / \mathrm{K}^{+}$-ATPase ion pump in male reproduction and embryo development," Reproduction, Fertility, and Development, vol. 29 , no. 8 , pp. 1457-1467, 2017. 
[47] R. Holm, M. S. Toustrup-Jensen, A. P. Einholm, V. R. Schack, J. P. Andersen, and B. Vilsen, "Neurological disease mutations of $\alpha 3 \mathrm{Na}^{+}, \mathrm{K}^{+}$-ATPase: structural and functional perspectives and rescue of compromised function," Biochimica et Biophysica Acta, vol. 1857, no. 11, pp. 1807-1828, 2016.

[48] T. H. Holm and K. Lykke-Hartmann, "Insights into the pathology of the $\alpha 3 \mathrm{Na}^{+} / \mathrm{K}^{+}$-ATPase ion pump in neurological disorders; lessons from animal models," Frontiers in physiology, vol. 7, p. 209, 2016.

[49] I. Dostanic, J. Schultz Jel, J. N. Lorenz, and J. B. Lingrel, “The $\alpha 1$ isoform of $\mathrm{Na}, \mathrm{K}-\mathrm{ATPase}$ regulates cardiac contractility and functionally interacts and co-localizes with the $\mathrm{Na} / \mathrm{Ca}$ exchanger in heart," The Journal of Biological Chemistry, vol. 279, no. 52, pp. 54053-54061, 2004.

[50] R. N. Correll, P. Eder, A. R. Burr et al., "Overexpression of the $\mathrm{Na}^{+} / \mathrm{K}^{+}$ATPase $\alpha 2$ but not $\alpha 1$ isoform attenuates pathological cardiac hypertrophy and remodeling," Circulation Research, vol. 114, no. 2, pp. 249-256, 2014.

[51] L. Liu, J. Wu, and D. J. Kennedy, "Regulation of Cardiac Remodeling by Cardiac $\mathrm{Na}^{+} / \mathrm{K}^{+}$-ATPase Isoforms," Frontiers in Physiology, vol. 7, p. 382, 2016.

[52] G. K. Yuen, S. Galice, and D. M. Bers, "Subcellular localization of $\mathrm{Na} / \mathrm{K}$-ATPase isoforms in ventricular myocytes," Journal of Molecular and Cellular Cardiology, vol. 108, pp. 158-169, 2017.

[53] V. A. Lakunina, K. M. Burnysheva, V. A. Mitkevich, A. A. Makarov, and I. Y. Petrushanko, "Changes in the receptor function of Na,K-ATPase during hypoxia and ischemia," Molekuliarnaia Biologiia (Mosk), vol. 51, no. 1, pp. 148-154, 2017.

[54] A. Askari, "The sodium pump and digitalis drugs: dogmas and fallacies," Pharmacology Research \& Perspectives, vol. 7, no. 4, article e00505, 2019.

[55] M. Obradovic, J. Stanimirovic, A. Panic et al., "Regulation of $\mathrm{Na}^{+} / \mathrm{K}^{+}$-ATPase by estradiol and IGF-1 in cardio-metabolic diseases," Current Pharmaceutical Design, vol. 23, no. 10, pp. 1551-1561, 2017.

[56] I. Hisatome, R. Ishiko, Y. Tanaka et al., "Trimetazidine inhibits $\mathrm{Na}^{+}, \mathrm{K}^{+}$-ATPase activity, and overdrive hyperpolarization in guinea-pig ventricular muscles," European Journal of Pharmacology, vol. 195, no. 3, pp. 381-388, 1991.

[57] A. A. McDonough and J. H. Youn, "Role of muscle in regulating extracellular $\left[\mathrm{K}^{+}\right]$," Seminars in Nephrology, vol. 25, no. 5, pp. 335-342, 2005.

[58] K. Overgaard, O. B. Nielsen, J. A. Flatman, and T. Clausen, "Relations between excitability and contractility in rat soleus muscle: role of the $\mathrm{Na}^{+}-\mathrm{K}^{+}$pump and $\mathrm{Na}^{+} / \mathrm{K}^{+}$gradients," The Journal of Physiology, vol. 518, no. 1, pp. 215-225, 1999.

[59] P. Zagorchev, E. Apostolova, V. Kokova, and L. Peychev, "Activation of KCNQ channels located on the skeletal muscle membrane by retigabine and its influence on the maximal muscle force in rat muscle strips," Naunyn-Schmiedeberg's Archives of Pharmacology, vol. 389, no. 4, pp. 439-446, 2016.

[60] S. A. Goldstein, "Sodium leak through K2P potassium channels and cardiac arrhythmia, an emerging theme," EMBO Molecular Medicine, vol. 9, no. 4, pp. 399-402, 2017.

[61] G. R. Li, C. P. Lau, A. Ducharme, J. C. Tardif, and S. Nattel, "Transmural action potential and ionic current remodeling in ventricles of failing canine hearts," American Journal of Physiology-Heart and Circulatory Physiology, vol. 283, no. 3, pp. H1031-H1041, 2002.
[62] J. Rose, A. A. Armoundas, Y. Tian et al., "Molecular correlates of altered expression of potassium currents in failing rabbit myocardium," American Journal of Physiology. Heart and Circulatory Physiology, vol. 288, no. 5, pp. H2077-H2087, 2005.

[63] X. J. Zhao, K. Lin, Y. Zhang et al., "Effects of allitridum on the transient outward potassium current in rats with heart failure," Journal of Geriatric Cardiology, vol. 13, no. 9, pp. 783-788, 2016. 